\title{
ANP promotes proliferation and inhibits apoptosis of ovarian granulosa cells by NPRA/PGRMC1/EGFR complex and improves ovary functions of PCOS rats
}

\author{
Qin Zheng ${ }^{1}$, Yulin Li ${ }^{1}$, Dandan Zhang ${ }^{1}$, Xinyuan Cui ${ }^{1}$, Kuixing Dai ${ }^{1}$, Yu Yang ${ }^{1}$, Shuai Liu ${ }^{*, 1}$, Jichun Tan $^{\star, 2}$ and Qiu Yan ${ }^{*, 1}$
}

Polycystic ovary syndrome (PCOS) is a complicated reproductive endocrine disease characterized by polycystic ovaries, hyperandrogenism and anovulation. It is one of the main causes of infertility. RU486 is an antagonist of progesterone receptor, and most commonly used as a contraceptive. However, whether RU486 is correlated with PCOS remains unclear. Atrial natriuretic peptide (ANP) is a small peptide with natriuretic and diuretic functions, and its availability to be used in PCOS treatment is unknown. Here, we showed that the serum ANP level was lower in PCOS patients than that in healthy women, and it was also decreased in the serum and ovarian tissues of RU486-induced PCOS rats compared with the control rats. We also found that RU486 inhibited the proliferation and promoted the apoptosis of human KGN ovarian granulosa cells by downregulating progesterone receptor membrane component 1 (PGRMC1). Meantime, ANP promoted the proliferation and inhibited the apoptosis of KGN cells through upregulating ANP receptor A (NPRA). The promotive effects of ANP on ovarian functions were mediated through the formation of an NPRA/PGRMC1/EGFR complex, which further activated MAPK/ERK signaling and transcription factor AP1. Moreover, ANP treatment reversed the PCOS symptoms, and improved the fertility of RU486-induced PCOS rats. Collectively, these findings highlight that RU486 is associated with the pathogenesis of PCOS, and ANP treatment may be a promising therapeutic option for PCOS.

Cell Death and Disease (2017) 8, e3145; doi:10.1038/cddis.2017.494; published online 26 October 2017

Polycystic ovary syndrome (PCOS) is one of the most incident reproductive endocrine diseases, with a prevalence ranging from 5 to $10 \%$ in women of reproductive age. ${ }^{1}$ The typical characteristics of PCOS include polycystic ovaries, hyperandrogenism and anovulation. ${ }^{2}$ Although the pathogenesis of PCOS is complex and largely unknown, the syndromes are often associated with hormone disorders, such as decreased progesterone and increased testosterone, estrogen and luteinizing hormone ( $\mathrm{LH})$, etc. ${ }^{3}$ Progesterone is a steroid hormone secreted mainly by ovarian granulosa cells and luteal cells. The function of progesterone is associated with follicular maturation, ${ }^{4}$ ovulation, ${ }^{5}$ embryonic development, ${ }^{6}$ endometrial receptivity and embryo implantation. ${ }^{7}$ It is also considered as an essential hormone for pregnancy maintenance. ${ }^{8}$ Patients with PCOS fail to form a corpus luteum, leading to a low level of progesterone and infertility. ${ }^{9,10}$ Progesterone dysfunction likely plays an important role in the pathophysiology of PCOS.

RU486 (mifepristone), a progesterone receptor antagonist, is an effective and the most commonly used contraceptive. The structure of RU486 is similar to that of progesterone, but its binding affinity to progesterone receptor is five times stronger than that of progesterone to progesterone receptor. ${ }^{11}$ Therefore, RU486 can strongly block the progesterone functions by competitively binding to progesterone receptor.
Furthermore, RU486 inhibits the development and maturation of follicles, resulting in the delayed occurrence of ovulation. ${ }^{12}$ Brown et al. ${ }^{13}$ found that most of the women exhibited anovulation after the continuous administration of RU486 (2 or $5 \mathrm{mg} /$ day) for 120 days, indicating that RU486 inhibited the development of follicles and ovulation. Other studies reported that the use of RU486 impaired corpus luteum formation and decreased progesterone production. ${ }^{14}$ Moreover, the development of the uterine endometrium and the establishment of endometrial receptivity, as well as the rate of pregnancy could also be influenced by RU486. ${ }^{15}$ Therefore, we speculated that the abuse of RU486 might be an etiological factor of PCOS, which was also correlated with infertility.

Recently, a new type of progesterone receptor was discovered: progesterone receptor membrane component (PGRMC), including PGRMC1 and PGRMC2. ${ }^{16}$ The expression of PGRMC1 is higher than that of PGRMC2, and it is mainly found in ovarian granulosa cells and luteal cells. ${ }^{17}$ PGRMC1 is also present in the fallopian tubes, ${ }^{18}$

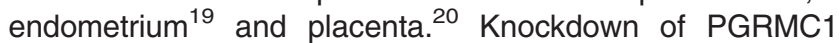
expression in mouse ovarian granulosa cells significantly reduced the number of antral follicles in the ovaries and the antiapoptotic capacity of progesterone, indicating that PGRMC1 may be involved in the growth and development of the ovaries, ${ }^{21}$ and the regulation of progesterone functions for

\footnotetext{
${ }^{1}$ Department of Biochemistry and Molecular Biology, Dalian Medical University, Liaoning Provincial Core Lab of Glycobiology and Glycoengineering, Dalian 116044, China and ${ }^{2}$ Centre for Auxiliary Human Reproduction, Shengjing Hospital of China Medical University, Shenyang 110004, China

*Corresponding author: S Liu or Q Yan, Department of Biochemistry and Molecular Biology, Dalian Medical University, Liaoning Provincial Core Lab of Glycobiology and Glycoengineering, 9 West Section, Lvshun South Road, Dalian 116044, China. Tel/Fax: +86 411 86110308; E-mail: liushuai_129@163.com or yanqiu63@126.com or J Tan, Centre for Auxiliary Human Reproduction, Shengjing Hospital of China Medical University, Shenyang 110004, China. Tel +86 024 96615-44312; E-mail: tjczjh@163.com

Received 22.5.17; revised 24.8.17; accepted 29.8.17; Edited by A Finazzi-Agrò
} 
granulosa cells. ${ }^{22}$ Abnormal PGRMC1 expression causes diseases, such as cancer $^{23}$ and infertility, ${ }^{24}$ etc. Schuster et al. ${ }^{25}$ compared the peripheral blood level of PGRMC1 level in women with regular menstrual cycle, PCOS and premature ovarian failure (POF) patients, and showed that the PGRMC1 level was lower in the PCOS and POF patients than that in the women with regular menstrual cycle. ${ }^{25}$ The results reveal that PGRMC1 may be associated with PCOS.

Atrial natriuretic peptide (ANP), a member of the natriuretic peptide family, is mainly secreted by atrial myocytes, which plays essential roles in regulating blood pressure, the salt and water balance and body fluid homeostasis based on its pharmacological functions in natriuresis and diuresis. ${ }^{26}$ In addition to atrial myocytes, ANP has also been found in ovarian oocytes, ${ }^{27}$ granulosa cells ${ }^{28}$ and the corpus luteum. ${ }^{29}$ Ovary-derived ANP can regulate ovarian functions, such as follicular growth and hormone production, through autocrine or paracrine manner. ${ }^{30}$ The serum ANP level was decreased in PCOS patients. ${ }^{31}$ Moreover, PCOS showed ovarian polycystic and physalides phenotypes. Taken together, these led us to hypothesize that ANP may be a novel therapeutic strategy for PCOS patients. The diverse physiological functions of ANP are manifested by its binding to the specific cell surface receptors. There are ANP-specific binding sites on ovarian granulosa cells and luteal cells. ${ }^{32,33}$ The binding of ANP to its specific receptors activates the downstream signaling pathways which are related to cell growth and apoptosis, etc. To date, three different subtypes of natriuretic peptide receptors (NPRs) have been identified: NPRA, NPRB and NPRC. ${ }^{34}$ Among the different NPRs, ANP shows the highest affinity for NPRA. ANP and NPRA were involved in the fertilization process. Hotchkiss et al. ${ }^{35}$ found that NPRA was expressed on blastocysts and embryonic stem cells, and involved in maintaining embryonic stem cells self-renewal and pluripotency. Zhang et al. ${ }^{36}$ also reported that the binding of ANP and NPRA induced sperm acrosome reaction occurred, whereas the receptor antagonist could eliminate the effect of ANP.

Till now, there is still a lack of effective therapies with low side effects because clinical presentations are complex and variable among PCOS patients. ${ }^{37}$ The major clinical treatments of PCOS patients include ovulation induction, antiandrogen, metabolic abnormality correction and ovarian drilling operation, etc. The main drugs used for PCOS is steroid hormones, which have many side effects. Hence, it is necessary to explore the etiology of PCOS and search for new non-steroid hormonal replacements to provide ideal treatment options for PCOS patients. ANP is a 28-amino-acid polypeptide, and its application in reproductive diseases has not yet been investigated. In the current study, we found that the serum ANP level was lower in PCOS patients than that in healthy women, and it was also reduced in the serum and ovary tissues of RU486-induced PCOS rats compared with that in control rats. ANP promoted the expression of NPRA and the formation of NPRA/PGRMC1/EGFR complex. Moreover, ANP treatment not only improved the morphology and functions of the ovary but also ameliorated the receptivity of the uterine endometrium and the pregnancy rate of PCOS rats.

\section{Results}

Decreased level of ANP in PCOS patients and PCOS rats, and improvement of ovary morphology and functions after ANP treatment. We first compared the level of ANP in the serum of PCOS patients and healthy women by ELISA (Figure 1a). The results showed that the serum ANP level in PCOS patients was significantly lower than that in healthy women. To confirm the alteration of ANP was associated with PCOS phenotypes, the RU486-induced PCOS rat model was used. As shown in Figure 1b, RU486-treated rats presented PCOS phenotypes, including polycystic, enlarged ovaries and thinner granular cell layer, etc. The changed serum hormone levels (Testosterone $(T)$, Progesterone $(P)$ and Estradiol $\left(E_{2}\right)$ ) also testified the pathogenesis of PCOS rats (Table 1). We further found that serum and ovarian ANP was significantly decreased in PCOS rats, compared with the control (Figures 1c and d), which was consistent with that of PCOS patients. Therefore, we hypothesized that ANP administration in PCOS rats may improve the ovarian morphology and functions. In the ANP treatment group, the thicker granular cell layer and elevated ANP expression were observed by immunohistochemical staining (Figure 1d). Additionally, to explore whether the embryo implantation potential was affected by the ANP level, we detected the alterations in implanted embryo number at gestational day (GD) 10 and ultrastructural changes in the uterine endometrium at GD4 by SEM. The results showed that the number of implanted embryos in the RU486 group was notably reduced, compared with that in the ANP treatment group (Figure 1e). The microvilli on the endometrial surface were decreased in the RU486 group, but recovered in the ANP group (Figure 1f). The above data suggest that ANP can be used as a new therapeutic drug for PCOS.

\section{Co-expression of NPRA/NPRC and PGRMC1 in human} ovarian granulosa cells and ovary tissues of PCOS rats. Based on the above results of decreased levels of ANP and progesterone in PCOS patients and rat model, we further detected the location and expression of NPRA/C and PGRMC1 in human ovarian granulosa cells (KGN) and ovary tissues of rats. The analysis of immunofluorescent staining showed that NPRA and PGRMC1, or NPRC and PGRMC1 were co-localized both in KGN cells (Figure 2a) and ovary tissues of rats (Figure 2b). The expression of NPRA, NPRC and PGRMC1 was lower in the ovary of PCOS rats than the control, whereas the levels were reversed in the ANP treatment group by real-time $\mathrm{PCR}$ and western blot (Figures $2 c-f$ ). Similar results were found in the expression changes of NPRA, NPRC and PGRMC1 in ovary tissues of rats of PCOS and the ANP group by immunohistochemical staining (Figure $2 \mathrm{~g}$ ). Our findings indicate that co-expression of NPRA/C and PGRMC1 may be involved in regulating ovary functions.

Downregulating the expression of PGRMC1 by RU486 inhibited the proliferation and promoted the apoptosis of human ovarian granulosa cells. To investigate the correlation and the roles of RU486 and PGRMC1 in ovary functions, KGN cells were treated with different RU486 concentrations 

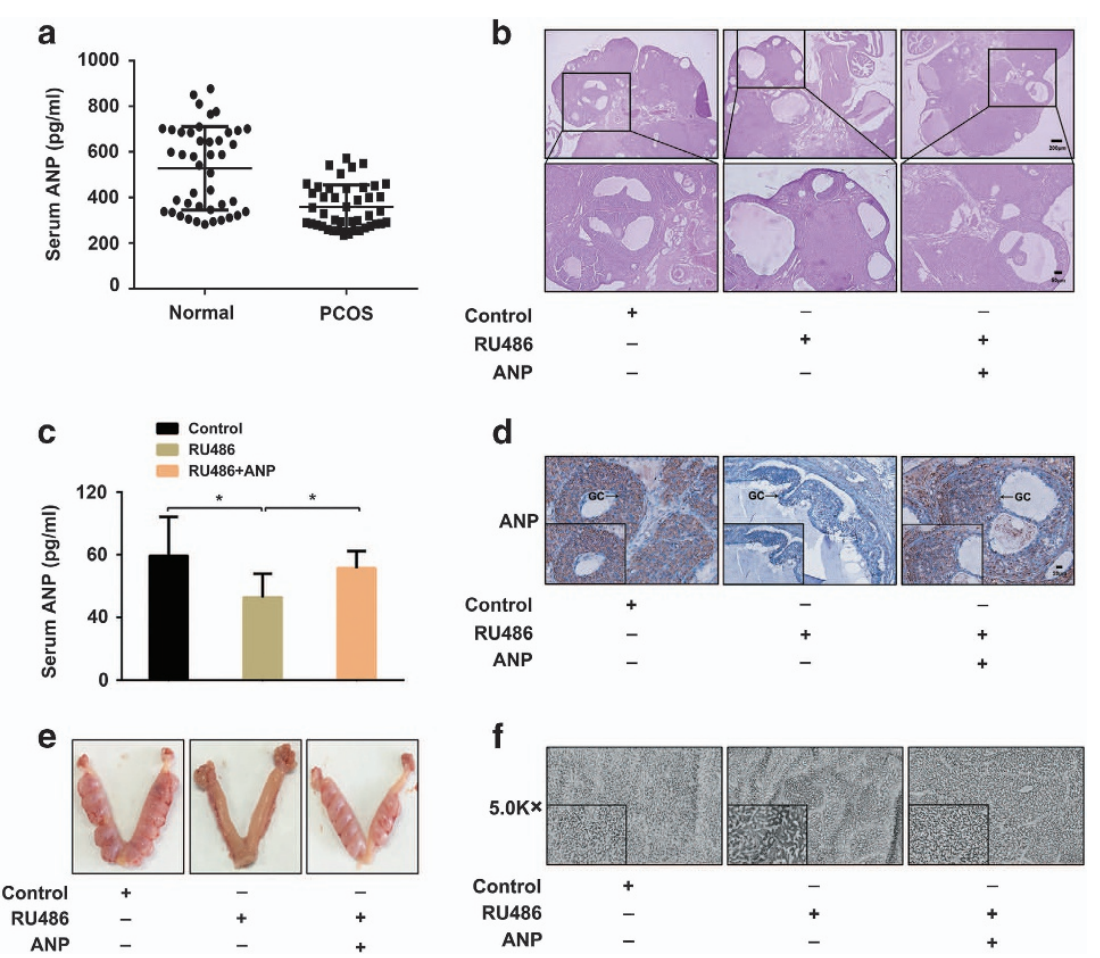

Figure 1 Expression of ANP in serum of PCOS patients and RU486-induced PCOS rats. (a) Analysis of ANP level in serum of PCOS patients and healthy women by ELISA. (b) Representative HE staining of the ovaries from RU486-induced PCOS rats and ANP treatment group. Bar $=200 \mu \mathrm{m}$ or Bar $=50 \mu \mathrm{m}$. (c) Analysis of ANP in serum of PCOS rats and ANP treatment group. (d) Immunohistochemical staining of ANP in PCOS rats and ANP treatment group. Bar $=20 \mu \mathrm{m}$. Significance was indicated by ${ }^{*} P<0.05$. (e) Implanted embryos in PCOS rats and ANP-treated rats. (f) Microvilli on uterine endometrium detected by scanning electron microscopy (SEM) in differently treated groups

Table 1 Endocrine parameters in serum of RU486-induced PCOS and ANP treatment rats

\begin{tabular}{|c|c|c|c|c|c|}
\hline & $P(n g / m l)$ & T (ng/ml) & $E_{2}(p g / m l)$ & FSH (ng/ml) & LH (mlU/ml) \\
\hline $\begin{array}{l}\text { Control group } \\
\text { RU486 group } \\
\text { ANP group } \\
P \text { (RU486/Control) } \\
P(\text { ANP/RU486) }\end{array}$ & $\begin{array}{c}438.40 \pm 109.42 \\
204.78 \pm 44.09 \\
378.41 \pm 13.60 \\
<0.01 \\
<0.001\end{array}$ & $\begin{array}{c}10.654 \pm 1.17 \\
16.274 \pm 1.25 \\
12.48 \pm 1.61 \\
<0.001 \\
<0.01\end{array}$ & $\begin{array}{c}634.63 \pm 70.49 \\
1247.00 \pm 236.80 \\
895.88 \pm 151.45 \\
<0.01 \\
<0.05\end{array}$ & $\begin{array}{c}210.00 \pm 20.55 \\
242.32 \pm 28.65 \\
239.28 \pm 34.21 \\
>0.05 \\
>0.05\end{array}$ & $\begin{array}{c}135.37 \pm 26.94 \\
296.40 \pm 47.95 \\
85.07 \pm 24.59 \\
<0.001 \\
<0.001\end{array}$ \\
\hline
\end{tabular}

$P$ : statistical significance $\left({ }^{\star} P<0.05 ;{ }^{* \star} P<0.01 ;{ }^{* \star *} P<0.001\right)$

$\left(0,10^{-6}, 10^{-5}, 10^{-4} \mathrm{M}\right)$ for different times $(0,24,48,72 \mathrm{~h})$. The results showed that RU486 significantly decreased the mRNA and protein levels of PGRMC1 in KGN cells (Figures $3 a-d)$. The culture medium of KGN cells treated with RU486, transfected with scramble RNA or PGRMC1 siRNA were collected to determine the alterations of hormone secretion. The ELISA results showed that both RU486 and PGRMC1 siRNA increased the secretion of testosterone (Figure $3 e$ ) and estrogen (Figure 3g), but decreased the level of progesterone (Figure $3 \mathrm{f}$ ). Then, we estimated the effects of RU486 and PCRMC1 on cell proliferation using CCK-8 (Figure $3 \mathrm{~h}$ ) and colony formation assay (Figure 3i). Compared with the control group, RU486 significantly weakened the proliferation ability of KGN cells, as did by PGRMC1 siRNA transfection. PCNA expression was downregulated after RU486 addition or PGRMC1 siRNA transfection as detected by western blot (Figure 3j) and immunofluorescent staining (Figure $3 \mathrm{k}$ ). The apoptosis of KGN cells was analyzed by TUNEL staining (Figure 3l), DAPI staining
(Figure 3m) and western blot (Figure 3n). Both RU486 and PGRMC1 siRNA treatments resulted in much higher rates of apoptosis than that of the control group. The treatments also downregulated the expression of the antiapoptosis protein $\mathrm{Bcl}-2$, while upregulating the expression of the pro-apoptosis proteins Bax, caspase 8 and caspase 9. The above data reveal that both RU486 and decreased expression of PGRMC1 can impair the functions of ovary cells.

ANP upregulated NPRA/C expression and promoted proliferation and inhibited apoptosis of KGN cells. We then investigated whether ANP could affect ovarian functions by regulating the expression of NPRA/C in KGN cells. The results revealed that ANP increased the expression levels of NPRA (Figures 4a, c, d and f) and NPRC (Figures 4b, c, e and f) both in mRNA and protein levels. The culture medium of KGN cells treated with ANP, RU486 or PGRMC1 siRNA was collected for the hormone analysis. ELISA results showed that the ANP treatment decreased the secretion of 

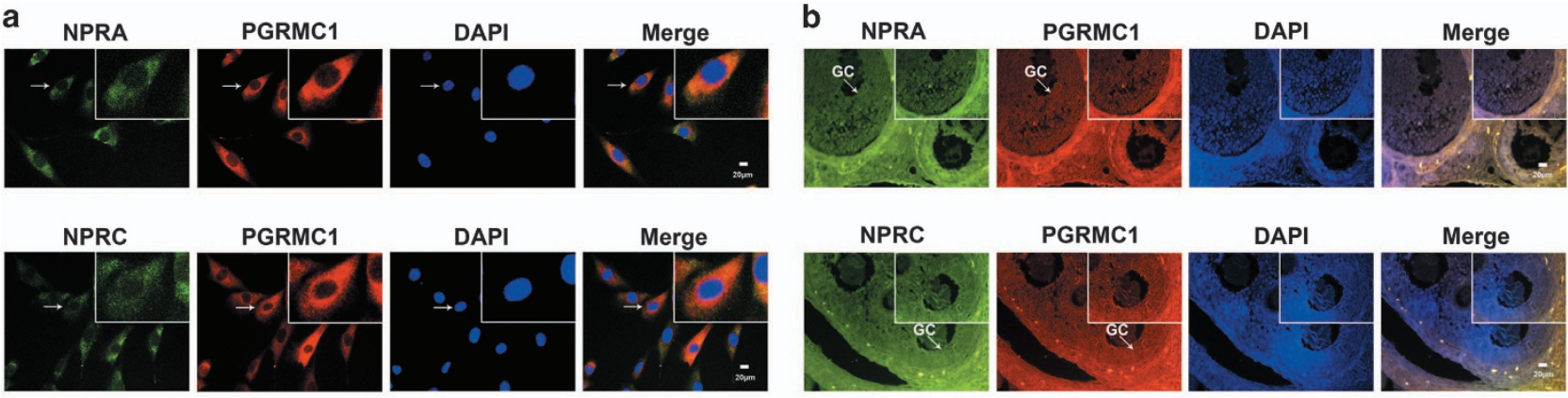

C
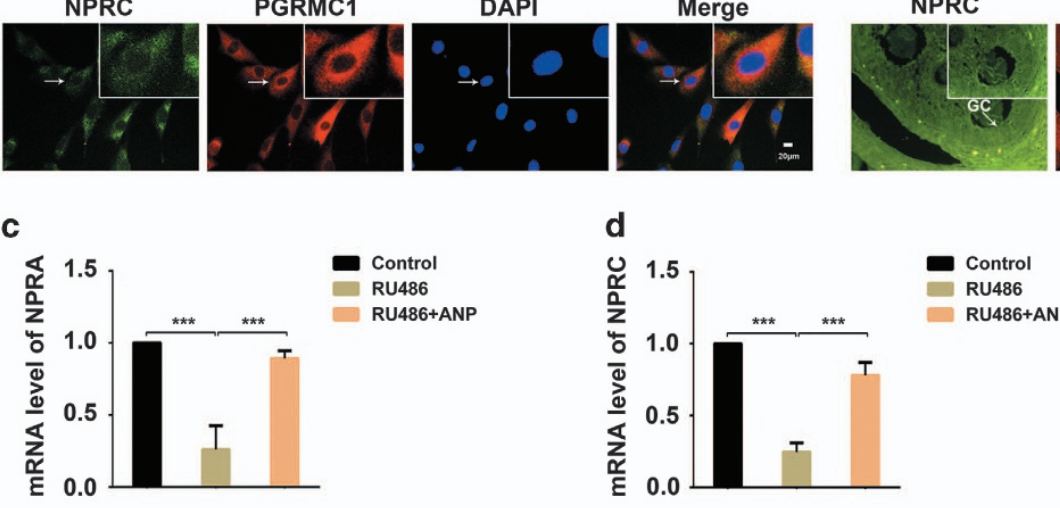

PGRMC1
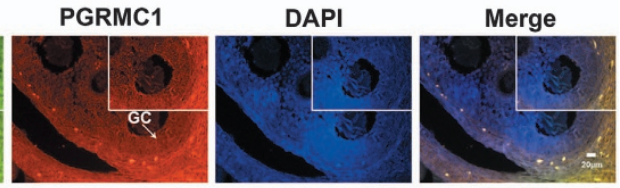

f
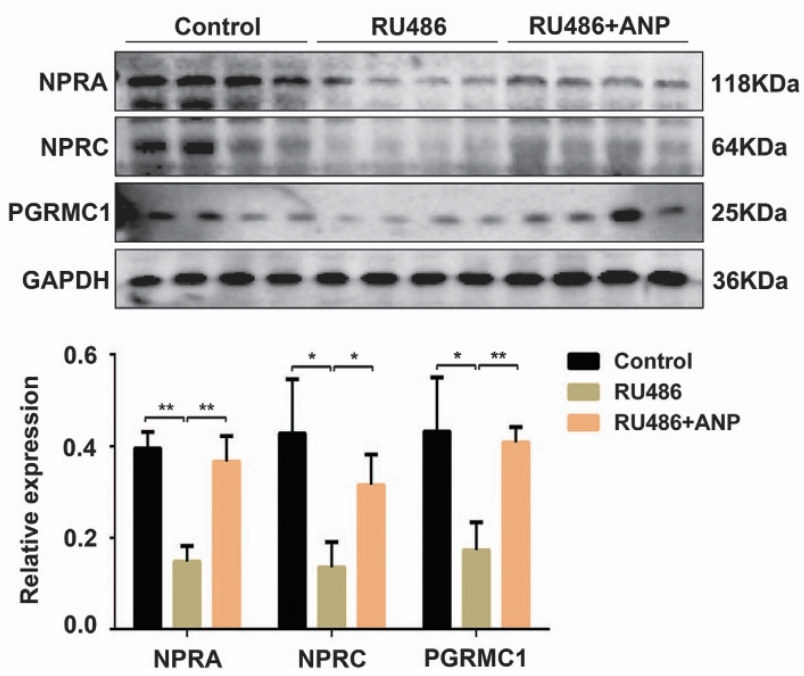
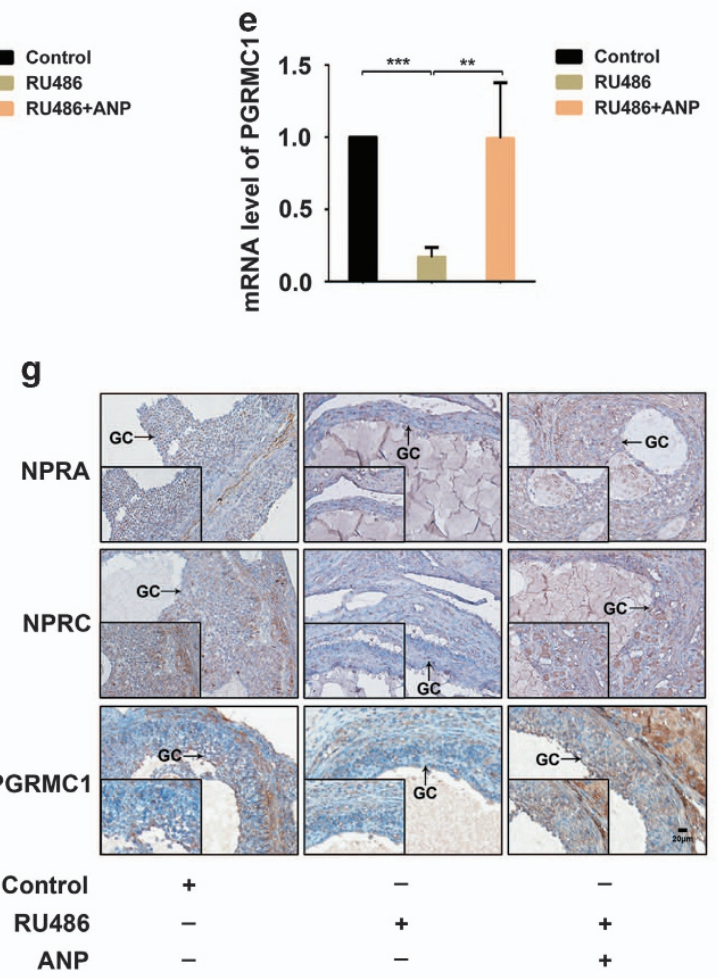

Figure 2 Co-expression of NPRA/NPRC and PGRMC1 in ovarian granulosa cells and PCOS rat model. (a) Representative immunofluorescent staining of NPRA/NPRC and PGRMC1 in human ovarian granulosa cells (KGN). NPRA and NPRC were visualized as green, and PGRMC1 as red. The nuclei were stained with DAPI (blue). Bar $=20 \mu \mathrm{m}$. (b) Representative images of Immunofluorescent staining of NPRA/NPRC and PGRMC1 in ovarian granulosa cells in rat. Green: NPRA/NPRC; Red: PGRMC1; Blue: DAPI. $\mathrm{Bar}=20 \mu \mathrm{m}$. (c, $\mathbf{d}$ and $\mathbf{e})$ mRNA levels of NPRA, NPRC and PGRMC1 in the ovary tissues of RU486-induced PCOS rats and the ANP treatment group by real-time PCR. (f) Expression and analysis of NPRA, NPRC and PGRMC1 in the ovary tissues of RU486-induced PCOS rats and the ANP treatment group by western blot. (g) Representative images of immunohistochemical staining of NPRA, NPRC and PGRMC1 in ovarian granulosa cells of PCOS and ANP-treated rats. Bar $=50 \mu \mathrm{m}$. Significance was indicated by ${ }^{\star} P<0.05,{ }^{* \star} P<0.01,{ }^{* \star *} P<0.001$

testosterone (Figure 4g) and estrogen (Figure 4i), but increased the level of progesterone (Figure $4 \mathrm{~h}$ ), and partly restored the alterations in three kinds of hormones caused by RU486 and PGRMC1 siRNA treatment. The effect of ANP on cell proliferation was detected by CCK-8 and colony formation assay. These results indicated that ANP accelerated the growth of KGN cells, and partially recovered the inhibitory effect by RU486 or PGRMC1 siRNA (Figures 4j and k). The analysis of PCNA expression by western blot (Figure 4l) and immunofluorescent staining (Figure $4 \mathrm{~m}$ ) further confirmed the effect of ANP promoting cell proliferation potential. TUNEL staining (Figure 4n), DAPI staining (Figure 40) and western blot (Figure $4 p$ ) were applied to determine the influence of
ANP on cell apoptosis. The results showed that ANP upregulated $\mathrm{Bcl}-2$ expression and downregulated Bax, caspase 8 and caspase 9 expression, while RU486 and PGRMC1 siRNA had opposite effects. The results suggest that ANP could facilitate proliferation and reduce the apoptosis of ovarian granulosa cells by upregulation of NPRA/C expression.

ANP promoted the proliferation of human ovarian granulosa cells through NPRA/PGRMC1/EGFR complex formation and activating MAPK/ERK signaling pathway. To explore the molecular mechanism underlying the ANPmediated regulation of ovarian functions, the interactions 
a

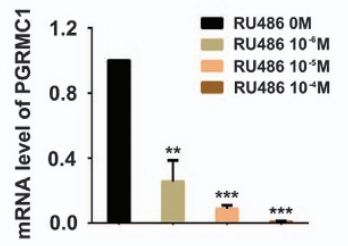

b

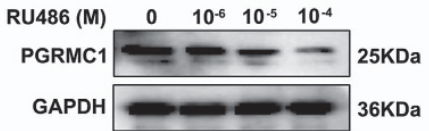

C

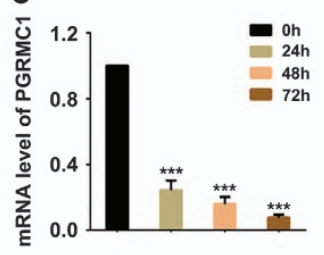

d

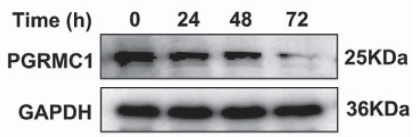

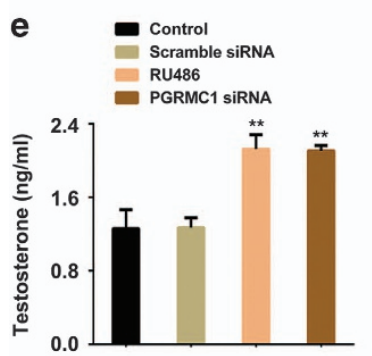
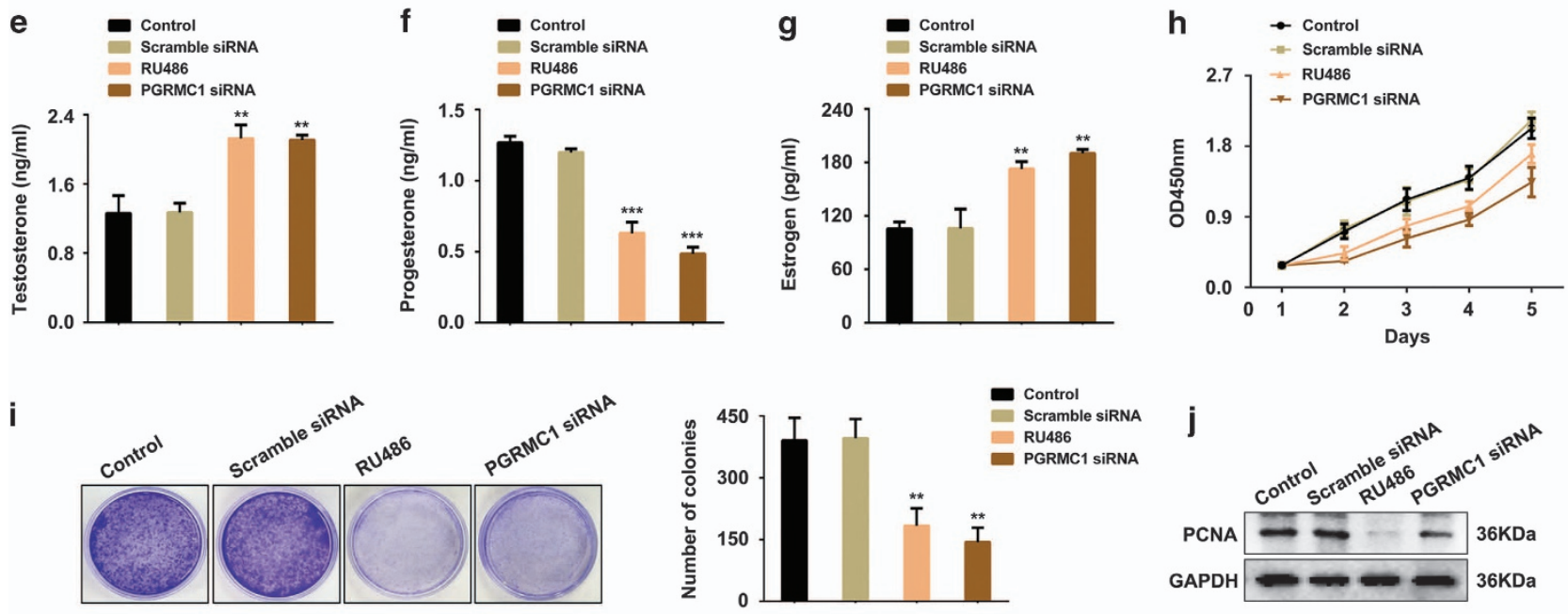
RU486 PGRMC1 siRNA

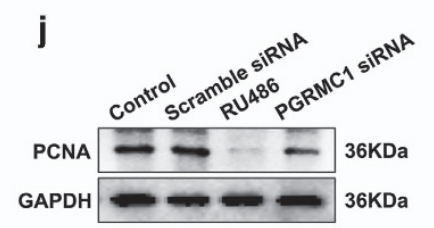

k
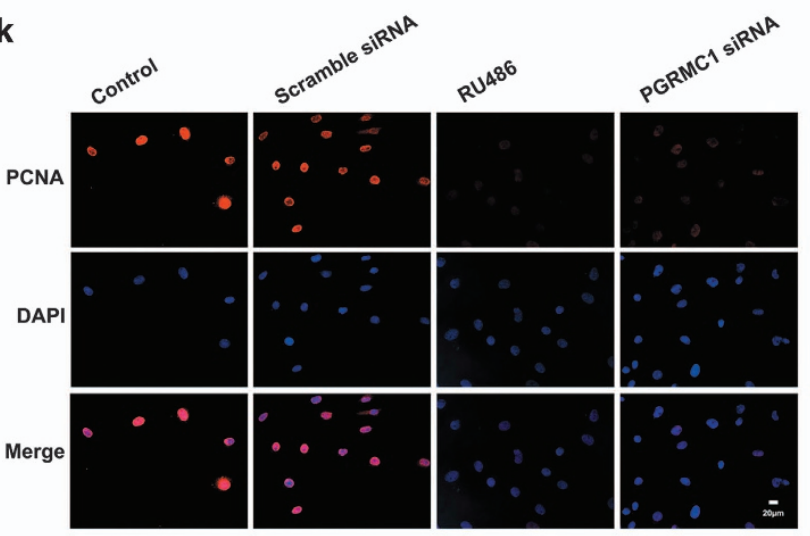

I
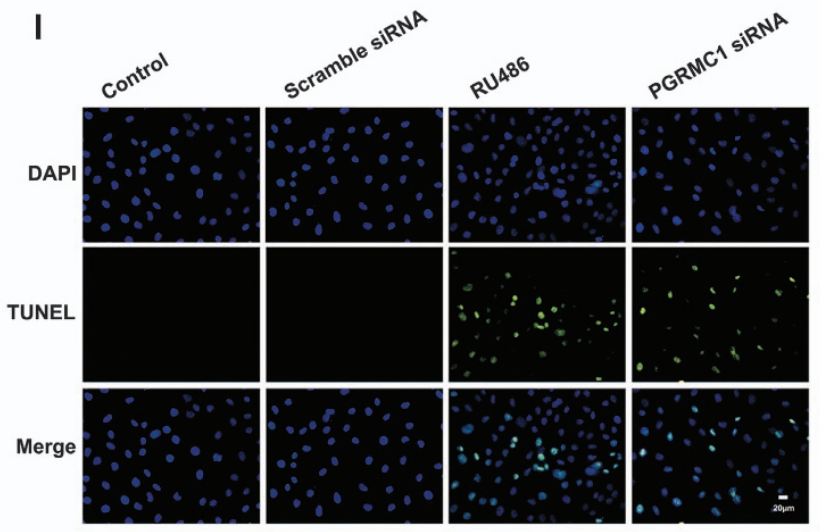

m
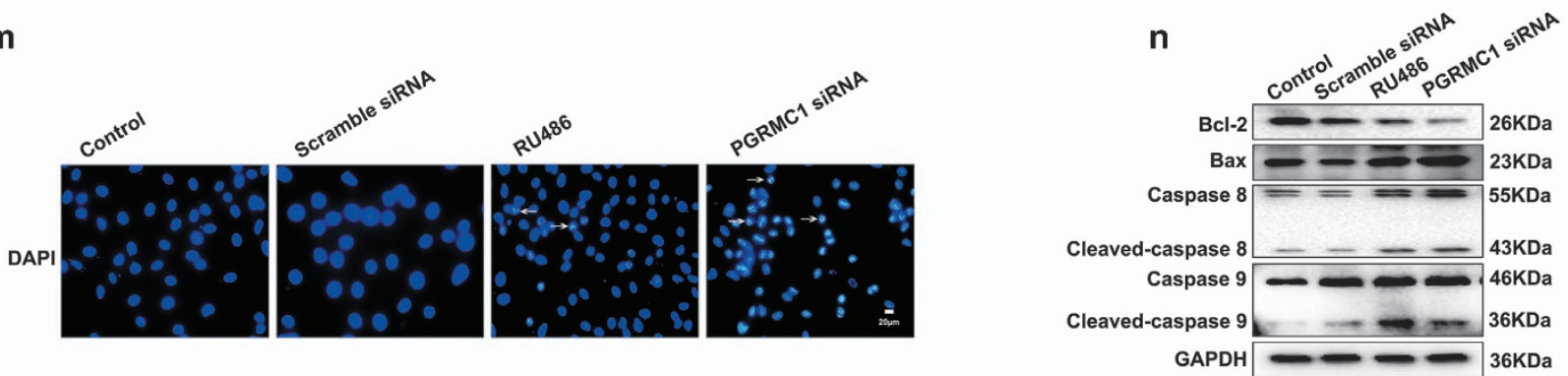

Figure 3 Downregulated PGRMC1 by RU486 suppressed proliferation and promoted apoptosis of KGN cells. (a and $\mathbf{b}$ ) KGN cells were treated with different concentrations of RU486 $\left(0,10^{-6}, 10^{-5}, 10^{-4} \mathrm{M}\right)$ for $48 \mathrm{~h}$. mRNA and protein levels of PGRMC1 were detected by real-time PCR and western blot. (c and d) KGN cells were treated with RU486 at the indicated times $(0,24,48,72 \mathrm{~h})$. Expression of PGRMC1 in KGN cells was analyzed by real-time PCR and western blot. (e-g) KGN cells were treated with RU486, transfected with scramble siRNA or PGRMC1 siRNA, respectively. Analysis of testosterone, progesterone and estrogen in the culture medium by ELISA. (h) CCK-8 assay for cell proliferation. (i) Colony formation assay. Representative images and statistical analysis were showed. (j) Protein level of PCNA in KGN cells was detected by western blot. (k) Immunofluorescent staining of PCNA in KGN cells. Red: PCNA; blue: DAPI. Bar $=20 \mu \mathrm{m}$. (I) Apoptosis analysis by TUNEL staining in KGN cells. Blue: DAPI; green: TUNEL. Bar $=20 \mu \mathrm{m}$. (m) DAPI staining for apoptosis analysis of KGN cells. Bar $=20 \mu \mathrm{m}$. (n) Western blot analysis of apoptosis-related proteins in KGN cells. Significance was indicated by ${ }^{* *} P<0.01,{ }^{* \star \star} P<0.001$ 
a
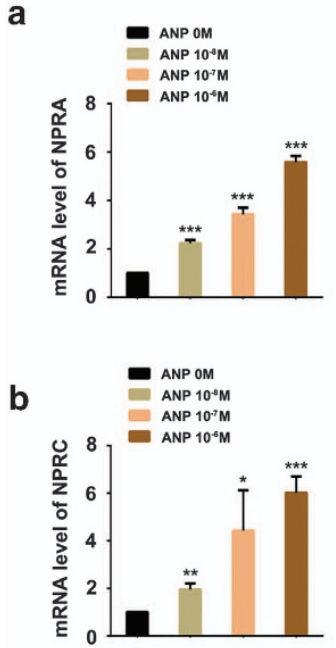

C
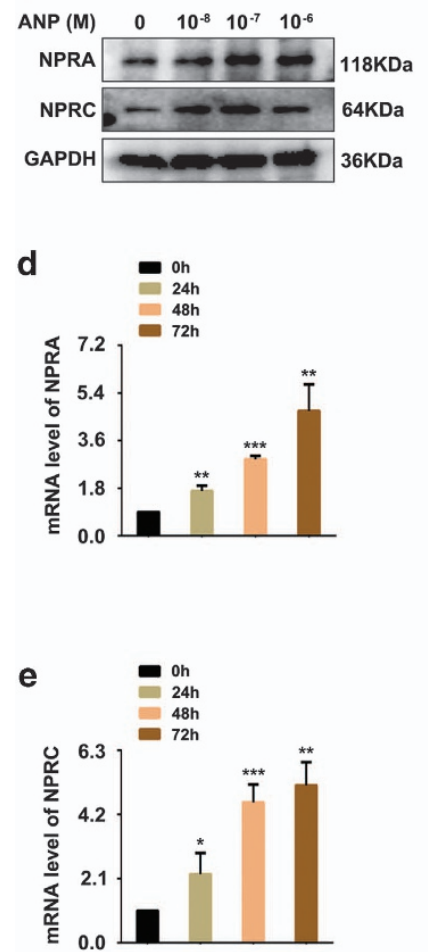

f

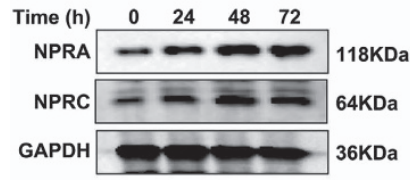

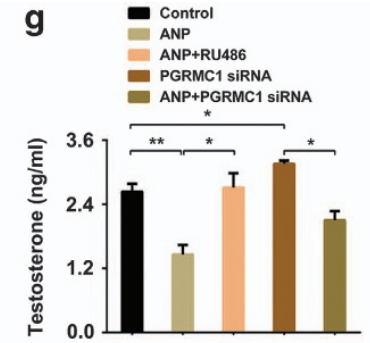
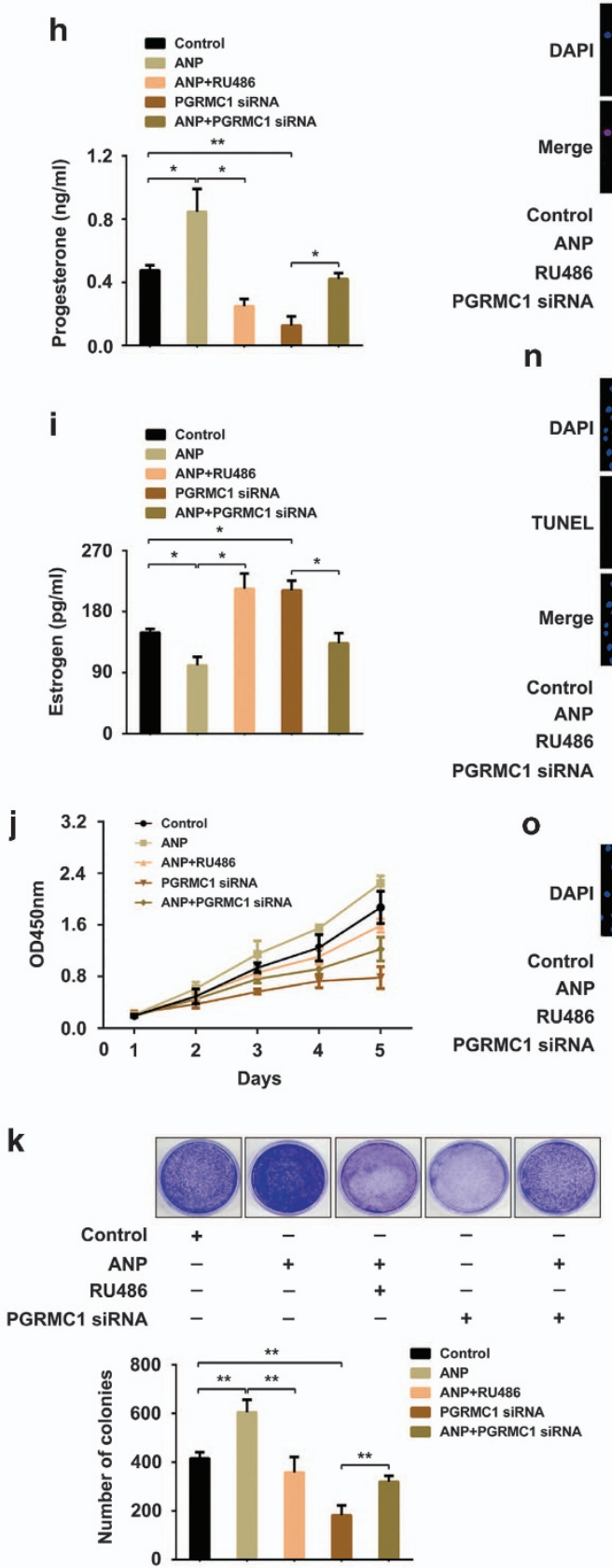

n

o
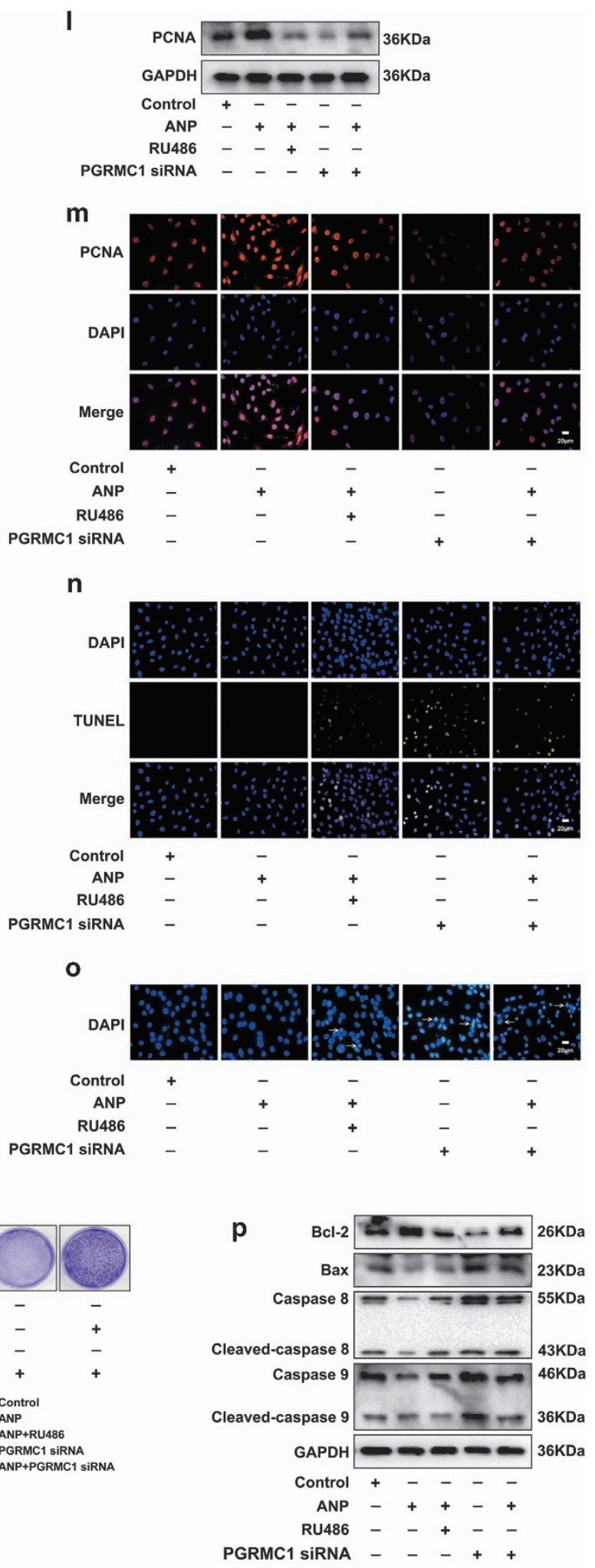

among NPRA, PGRMC1 and EGFR, as well as the activation of MAPK/ERK signaling pathway were analyzed. KGN cells were pretreated with RU486 with or without ANP, and then immunoprecipitation (IP) was used to detect the relationships among NPRA, PGRMC1 and EGFR. As shown in Figures 5a and $b$, NPRA, PGRMC1 and EGFR could form a binding complex. It was further confirmed by the regulatory effects of ANP and RU486 on the complex constitution and 
Figure 4 ANP upregulated NARA/C expression and promoted the proliferation and inhibited the apoptosis of KGN cells. (a-c) KGN cells were treated with different concentrations of ANP $\left(0,10^{-8}, 10^{-7}, 10^{-6} \mathrm{M}\right)$ for $48 \mathrm{~h}$. mRNA and protein levels of NPRA/C were detected by real-time PCR and western blot. (d-f) KGN cells were treated with ANP at the indicated times $(0,24,48,72 \mathrm{~h})$. mRNA and protein levels of NPRA/C detected by real-time PCR and western blot. ( $\mathbf{g}$-i) KGN cells were treated with ANP, or ANP and RU486, PGRMC1 siRNA, or ANP and PGRMC1 siRNA, respectively. Levels of testosterone, progesterone and estrogen were measured by ELISA in the culture medium of KGN cells. (j) CCK-8 assay for cell proliferation. (k) Colony formation assay. Representative images and statistical analysis were showed. (I) Western blot analysis of protein level of PCNA in KGN cells. (m) Immunofluorescent staining of PCNA in KGN cells. Red: PCNA; Blue: DAPI. Bar $=20 \mu \mathrm{m}$. (n) TUNEL staining for apoptosis analysis of KGN cells. Blue: DAPI; Green: TUNEL. Bar $=20 \mu \mathrm{m}$. (o) DAPI staining for morphological evaluation of apoptotic cells. Bar $=20 \mu \mathrm{m}$. (p) Western blot analysis of apoptosis-related proteins in KGN cells. Significance was indicated by ${ }^{*} P<0.05,{ }^{* \star} P<0.01,{ }^{* \star \star} P<0.001$

\section{a}

IP: NPRA

IB: PGRMC1/EGFR

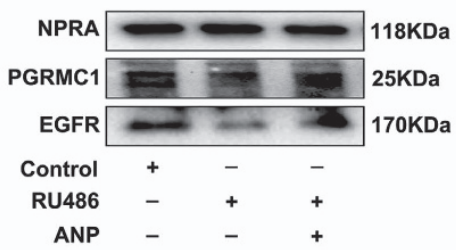

C

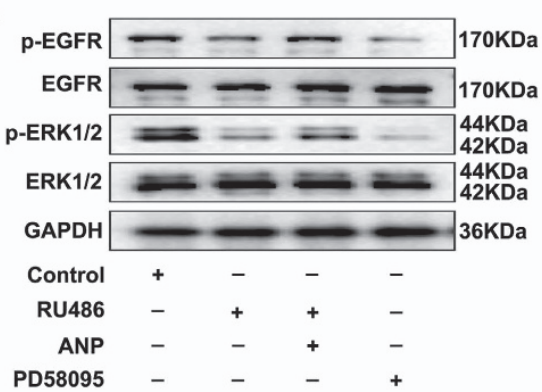

d

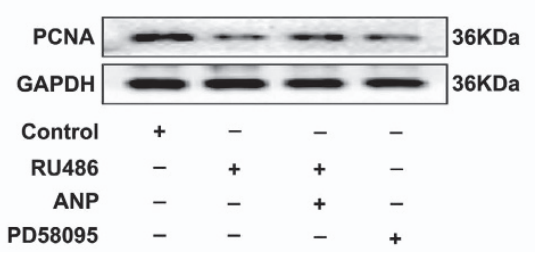

b

IP: PGRMC1

IB: NPRA/EGFR
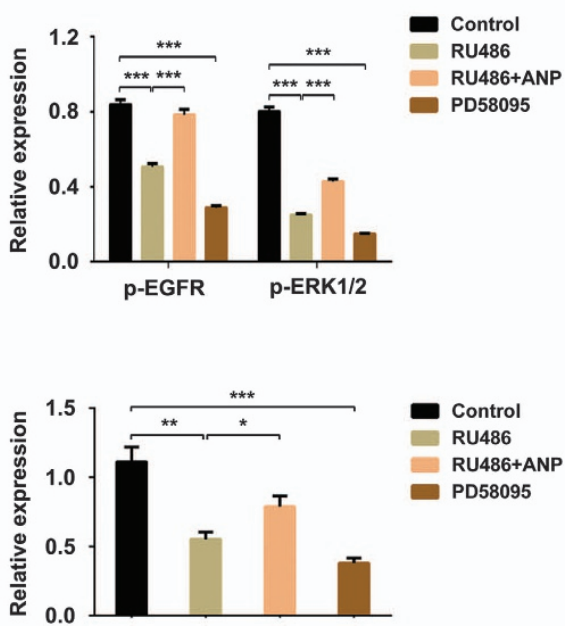

Figure 5 NPRA/PGRMC1/EGFR complex promoted the proliferation of ovarian granulosa cells through the MAPK/ERK signaling pathway. KGN cells were treated with RU486, or RU486 and ANP, respectively. (a) Immunoprecipitation (IP): anti-NPRA pulled down proteins. Immune blot (IB): levels of PGRMC1 and EGFR were detected by western blot. (b) IP: anti-PGRMC1 pulled down proteins. IB: levels of NPRA and EGFR were detected by western blot. (c) KGN cells were treated with RU486, RU486 and ANP, or the inhibitor of MAPK/ERK (PD58095). Phosphorylation of EGFR (p-EGFR) and ERK1/2 (p-ERK1/2) were detected by western blot. (d) Western blot analysis of PCNA expression in KGN cells. Statistical analysis was shown. Significance was indicated by ${ }^{*} P<0.05,{ }^{\star \star} P<0.01,{ }^{* \star} P<0.001$

downstream EGFR activation. In addition, fewer complexes by RU486 inhibited the activation of EGFR signaling pathway, which was verified by the addition of PD58095 (an inhibitor of MAPK/ERK signaling pathway) (Figure $5 \mathrm{c}$ ). The decrease in the complex formation further inhibited the PCNA expression, whereas the increased complexes induced by ANP could partly recover the PCNA level (Figure $5 d$ ). The results manifested that ANP plays an important role in ovarian functions through NPRA/PGRMC1/EGFR complex formation and activating the downstream MAPK/ERK signaling pathway.

ANP promoted cell proliferation of human and rat ovarian granulosa cells by activating AP1. Having observed the effects of ANP on the proliferation and apoptosis of KGN cells, we explored whether ANP could promote proliferation through stimulating the activation of transcription factor AP1. KGN cells were pretreated with ANP, PGRMC1 siRNA or TKI (an inhibitor of EGFR activation). The results indicated that ANP increased the activation of AP1 ( $p-c-F o s$ and $p-c-J u n)$, and upregulated the expression of PCNA, while PGRMC1 siRNA and TKI inactivated AP1, and downregulated PCNA expression in human KGN cells (Figures $6 a$ and b). The immunohistochemical staining (Figure 7a) and western blot (Figure $7 \mathrm{~b}$ ) results showed decreased levels of PCNA, p-c-Fos and p-c-Jun in the ovary tissues of PCOS rats induced by RU486, whereas the inhibitory effect were reversed in ANP-treated rats. These results suggest that ANP promotes ovarian granulosa cells proliferation by activating AP1 both in vitro and in vivo. 

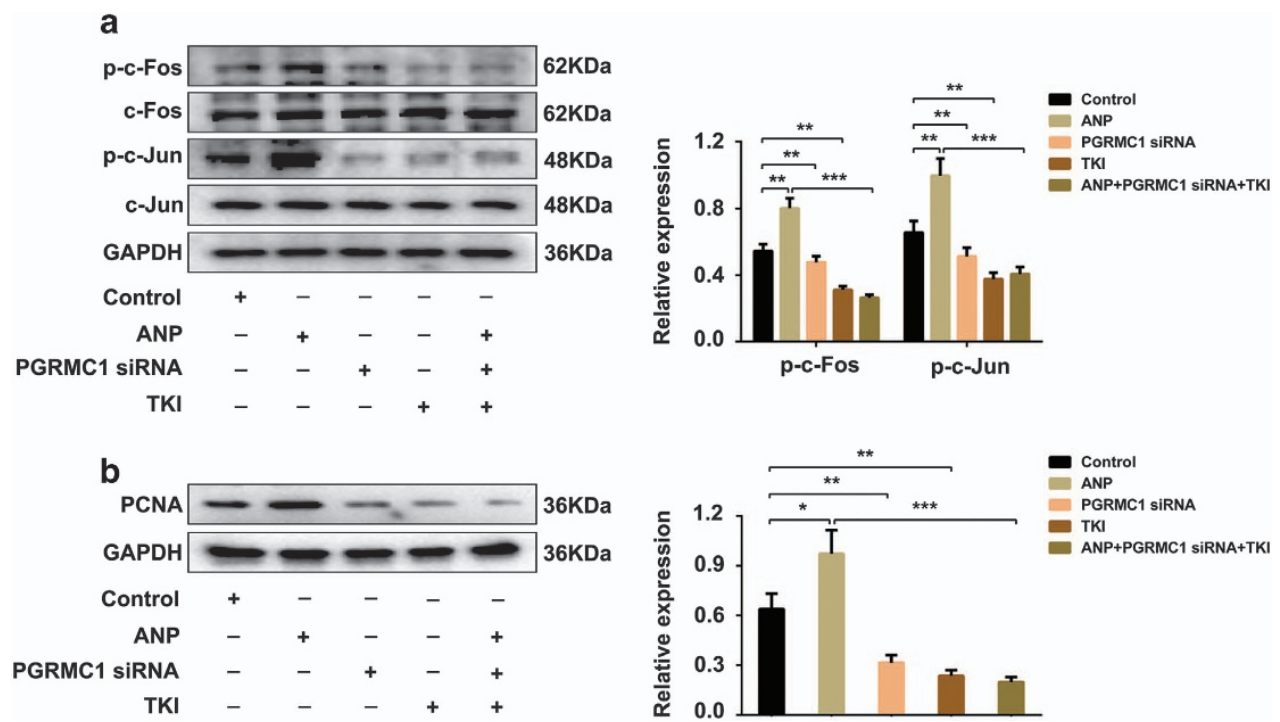

Figure 6 ANP activated AP1 and upregulated the expression of PCNA. KGN cells were treated with ANP, transfected with PGRMC1 siRNA, EGFR inhibitor (TKI), or ANP with PGRMC1 siRNA and TKI, respectively. (a) Western blot analysis of activation of AP1 (p-c-Fos, p-c-Jun). (b) Level of PCNA was detected by western blot. Significance was indicated by ${ }^{*} P<0.05,{ }^{\star \star} P<0.01,{ }^{\star \star *} P<0.001$
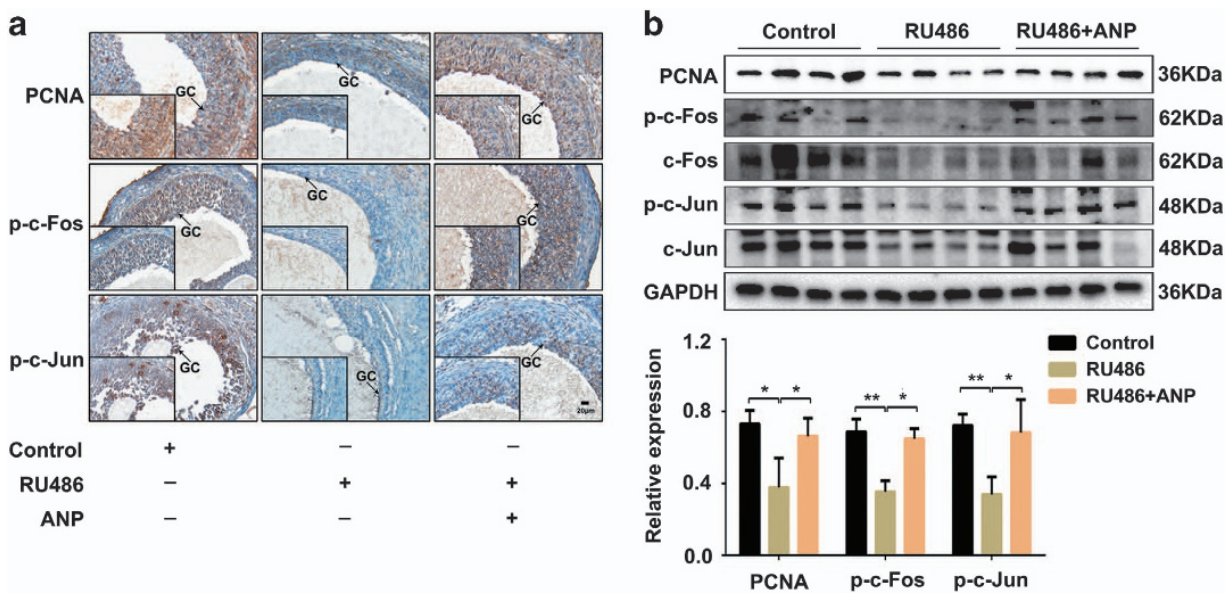

Figure 7 ANP promoted the expression of PCNA by activating AP1 in RU486-induced PCOS rats. PCOS rat model was established by RU486 treatment with or without ANP. (a) Representative images of immunohistochemical staining of PCNA and AP1 (p-c-Fos, p-c-Jun) in the ovarian granulosa cells (GC) of PCOS rats and ANP treatment group. $B a r=20 \mu \mathrm{m}$. (b) Western blot analysis of PCNA and activation of AP1 in the ovary tissues of PCOS rats and ANP treatment group. The representative bands and statistical analysis were shown. Significance was indicated by ${ }^{*} P<0.05,{ }^{* *} P<0.01$

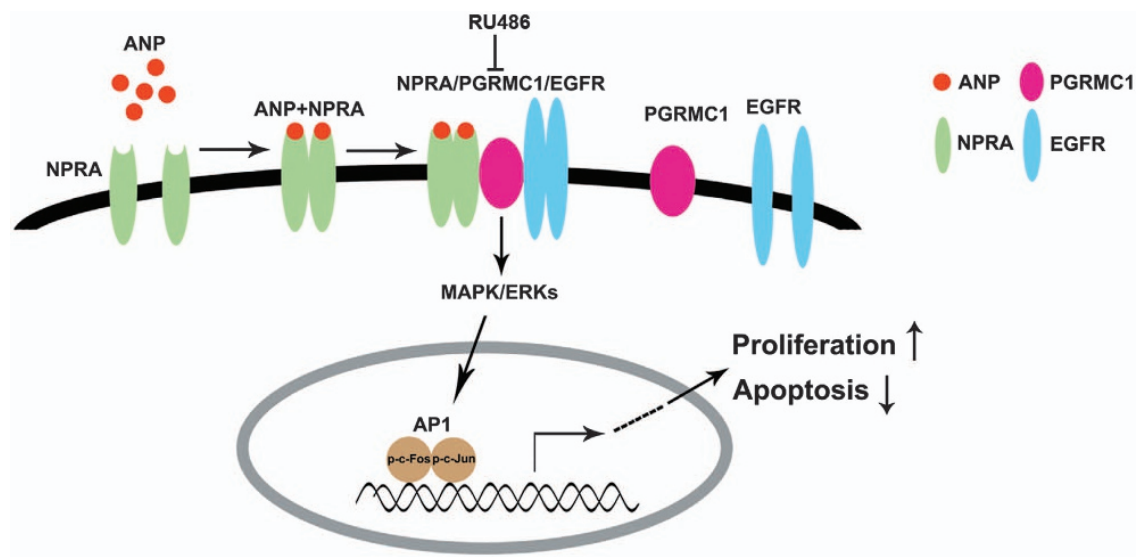

Figure 8 Illustrative model of the mechanism of ANP on proliferation and apoptosis of ovarian granulosa cells 


\section{Discussion}

The relationship between ANP and PCOS has not been well studied. Lauria et al. ${ }^{31}$ reported a lower serum ANP level in PCOS patients than in that of age- and BMI-matched controls. ${ }^{31}$ We also found that the serum ANP level decreased in PCOS patients, and in the RU486-induced PCOS rats by ELISA assay. We further confirmed that decreased ANP was correlated with the aberrant morphology and functions by the PCOS rat model. In addition, by in vivo and in vitro experiments, we found that ANP positively regulated the ovarian functions by promoting proliferation and inhibiting apoptosis of ovarian granulosa cells. The data revealed that ANP maybe a potential therapeutic target for PCOS. Currently, clomiphene citrate $(\mathrm{CC})$ is the first-line treatment for inducing ovulation, and it is a type of anti-estrogen steroid preparation. ${ }^{38}$ However, $\mathrm{CC}$ treatment often present many side effects. For example, $\mathrm{CC}$ can cause endometrial thinning, ${ }^{39}$ which is not conducive to embryonic implantation, thus leading to decreased pregnancy rates. ${ }^{40}$ ANP is mostly used for heart and kidney diseases by intravenous infusion during surgical operations. ${ }^{41,42}$ In our study, we found that ANP treatment effectively ameliorated most of the symptoms found in PCOS rats, including polycystic ovaries, hyperandrogenism and hormone production, as well as the pregnancy rate. The study provides the theoretical basis for the treatment of PCOS with ANP, and the pharmacokinetics and clinical trials need to be further conducted.

$\mathrm{RU} 486$ is a progesterone receptor antagonist that abolishes the functions of progesterone, such as embryonic development, endometrial receptivity and ovarian functions. ${ }^{43,44}$ Marions et al. ${ }^{45}$ reported that RU486 administration could affect the ovulation process. Furthermore, RU486 could prevent endometrial maturation and proliferation with high doses exceeding $10 \mathrm{mg}$ or repeatedly administered low doses. ${ }^{46}$ Gemzell-Danielsson et al. ${ }^{47}$ found that if RU486 was administered at high doses after ovulation, it would inhibit uterine secretory phase progression and embryo implantation through a direct effect on the endometrium. Currently, the regular use of RU486 as contraceptive to avoid pregnancy in young women of childbearing age is common. The long-term use of RU486 may lead to the occurrence of infertility, which can partly explain the increased incidence of infertility in recent years. Thus, we explored the pathogenic mechanism of RU486 in PCOS. A PCOS animal model is useful for detailed molecular studies of changes in histopathology and hormone synthesis, etc. RU486 could induce the similar features of human PCOS, such as anovulation, enlarged ovaries containing atretic follicles or follicular cysts, as well as increased testosterone, estrogen and $\mathrm{LH}$ levels. ${ }^{48}$ Lakhani et al. ${ }^{49}$ successfully established the PCOS rat model using RU486, which was used to investigate vascular deficits. In our study, we also established the RU486-induced PCOS rat model, which present characteristic polycystic and enlarged ovaries, as well as the consistently changed serum hormones. The inhibitory functions of RU486 on ovary were further confirmed by in vitro and in vivo study. Furthermore, RU486 impaired endometrial development and pregnancy rate. These results suggest that RU486 may lead to undesirable ovarian development and functions. Therefore, women of reproductive age should use RU486 cautiously.

The formation of NPRA/PGRMC1/EGFR complex is the molecular basis by which ANP promotes the growth and inhibits the apoptosis of ovarian granulosa cells. This has not yet been reported. ANP exerts the reproductive activities, like hormone production ${ }^{50}$ and sperm acrosome reaction, ${ }^{36}$ by binding to NPRA/C. PGRMC1 is located on the cell membrane and regulates ovarian development and functions of ovarian granulosa cells. In this study, we found that ANP upregulated NPRA expression and promoted proliferation and inhibited apoptosis, and co-expression of NPRA and PGRMC1 in human ovarian granulosa cells and ovary tissues of PCOS rats were observed. Furthermore, inhibition of PGRMC1 expression by RU486 could be restored by addition of ANP. The above data suggest the co-existence of molecular interaction between NPRA and PGRMC1. EGFR plays a critical role in cell growth and differentiation, and is involved in many reproductive processes, including implantation and decidualization. ${ }^{51}$ Ahmed et al. ${ }^{52}$ reported that EGFR was one of the most potent receptor-tyrosine kinases driving tumor proliferation, and PGRMC1 promoted several cancer phenotypes, at least in part, by binding EGFR and stabilizing plasma membrane pools of the receptor. In this study, based on the fact that RU486 inhibited, whereas ANP, NPRA and PGRMC1 promoted the proliferation of ovarian granulosa cells, we further explore whether EGFR is associated with NPRA and PGRMC1-mediated ovary functions. Except the colocalization between NPRA and PGRMC1 in both human ovarian granulosa cells and rat ovary tissues by immunofluorescence observation, the IP results further validated the interaction among NPRA, PGRMC1 and EGFR in KGN cells. RU486 decreased NPRA/PGRMC1/EGFR complex formation. However, ANP could reverse the effects of RU486 on complex formation. The NPRA/PGRMC1/EGFR complex further activated the MAPK/ERK signaling pathway and induced transcription factor AP1 expression and activation, which facilitated proliferation and inhibited apoptosis of KGN cells (Figure 8). These findings demonstrate that ANP improves ovarian functions via the NPRA/PGRMC1/EGFR complex, which is involved in the pathogenesis and treatment strategy of PCOS.

In conclusion, the serum ANP level in PCOS patients was decreased compared with healthy women. ANP treatment reversed the phenotypes of PCOS rats induced by RU486. RU486 inhibited, whereas ANP promoted, the formation of the NPRA/PGRMC1/EGFR complex, which influence the proliferation and apoptosis of ovarian granulosa cells. The study suggests that the use of RU486 may lead to the occurrence of PCOS, and ANP is a novel option as a non-steroid hormonal drug for PCOS treatment.

\section{Materials and Methods}

Ethics statement. The clinical samples obtained from Shengjing Hospital of China Medical University, and signed informed consent forms were obtained from all of the subjects. The research got the approval of the clinical ethics review board of China Medical University and Dalian Medical University. The procedures of animal experiments were carried out in conformity with the guidance for the care and use of laboratory animals in Dalian Medical University. 
Serum sample. Serum samples were obtained from Shenging Hospital of China Medical University from 2015 to 2016. The diagnosis of PCOS followed the Rotterdam criteria of 2003: oligoovulation, hyperandrogenism or hyperandrogenemia and the morphology of polycystic ovaries. The exclusion of related disorders include Cushing's syndrome, androgen-producing tumors and congenital adrenal hyperplasia. The healthy control group was with regular menstrual cycle which excluded from other gynecological abnormalities like hirsutism and endocrine dysfunction. The serum samples collected from healthy control group and PCOS patients were used to detect ANP level.

Cell culture. A steroidogenic human granulosa cell-like tumor cell line (KGN) was obtained from RIKEN (Tokyo, Japan). The KGN cells were maintained in DMEM/F12 supplemented with $10 \% \mathrm{FBS}, 100 \mathrm{U} / \mathrm{ml}$ penicillin and $100 \mu \mathrm{g} / \mathrm{m}$ streptomycin in a humidified atmosphere of $5 \% \mathrm{CO}_{2}$ at $37^{\circ} \mathrm{C}$. The growth medium was changed every 2-3 days.

Animal model. Female Sprague-Dawley adult rats (aged 12-14 weeks) were selected, bred and housed with free access to water and food. The rats that showed at least two consecutive estrous cycles by vaginal smear examination were chosen for further study. The rats were injected with RU486 (mifepristone; Sigma-Aldrich, St. Louis, MO, USA) in olive oil $(2 \mathrm{mg} / 0.1 \mathrm{ml} / 100 \mathrm{~g}$ body weight/day) daily subcutaneously, which was begun on the first day of estrous cycle. Control mice were injected with olive oil only. ANP was prepared $(2 \mu \mathrm{g} / \mathrm{kg})$ and applied by intraperitoneal administration. Samples, including serum and ovarian tissues, were collected for further study.

Transfection. Synthetic siRNA of PGRMC1 (GenePharma, Shanghai, China) was delivered into cells with Lipofectamine 2000 (Invitrogen, Carlsbad, CA, USA) according to the protocols. The siRNA sequences of PGRMC1 were $5^{\prime}$ GGUGUUCGAUGUGACCAAATT-3' and 5'-UUUGGUCACAUCGAACACCTT-3'. The protein and RNA samples were collected and experiments were performed $48 \mathrm{~h}$ after transfection.

Immunofluorescence. Frozen tissue sections from control and PCOS rat model were fixed in $4 \%$ paraformaldehyde at room temperature following with $20 \%$ sucrose for $48 \mathrm{~h}$. The tissues were embedded with OCT and sliced at $-20^{\circ} \mathrm{C}$. After fixed with acetone, goat serum was used to block at room temperature for $2 \mathrm{~h}$. The primary antibodies mouse anti-NPRA (1:50; Santa Cruz Biotechnology, CA, USA) and NPRC (1:100; Santa Cruz Biotechnology, CA, USA), rabbit anti-PGRMC1 (1:100; Cell Signaling, Danvers, MA, USA) and PGRMC2 (1:50; Cell Signaling) were incubated at $37^{\circ} \mathrm{C}$ for $2 \mathrm{~h}$. Washing with PBS, TRITC-conjugated goat antirabbit IgG (1:100; ZSGB-BIO, Shanghai, China) and FITC-conjugated goat antimouse IgG (1:100; Sigma-Aldrich, St. Louis, MO, USA) were incubated for $1 \mathrm{~h}$ at $37^{\circ} \mathrm{C}$ following treatment with DAPI (1:1000; Beyotime, Shanghai, China) for 3 min. The immunofluorescent images were taken with an inverted microscope (Olympus, Tokyo, Japan).

Cells grown on coverslips were fixed with $4 \%$ paraformaldehyde for 20 min at room temperature following incubation with $0.1 \%$ Triton X-100 for 15 min. After blocking with goat serum, cells were incubated with rabbit anti-PCNA (1:200; Proteintech, Wuhan, China) at $4{ }^{\circ} \mathrm{C}$ overnight. TRITC-conjugated goat anti-rabbit IgG was incubated for $1 \mathrm{~h}$ and DAPI (1:1000) for $3 \mathrm{~min}$. Immunofluorescent staining was photographed with an inverted microscope.

ELISA. Commercial ELISA kits (Elabscience, Wuhan, China) were used to detect the hormones (progesterone, testosterone, estrogen, LH, FSH) and ANP levels both in human serum and rat serum according to the manufacturer's instructions. The absorbance at $450 \mathrm{~nm}$ was measured and recorded. Three samples from each group were tested.

RNA isolation and real-time PCR. Total RNA was isolated using TRizol reagent (TaKaRa, Dalian, China) according to the manufacture's manual. A total of $1 \mu \mathrm{g}$ RNA was used for cDNA synthesis with PrimeScript RT Master Mix Perfect Real Time Kit (TaKaRa). The primers sequences of human were as follows: NPRA, forward 5'-GGGATACAGTCAACACAGCCTCAA-3', reverse 5'-CGAAGCTCCAGCTCGA AAC-3'; NPRC, forward 5'-AGATGCCAACGGAGACCGATA-3', reverse 5'-ACATTC GGCCGCATTTCA-3'; PGRMC1, forward 5'-CGGGCTGCTGCATGAGATT-3', reverse 5'-GCACGATCTTGTAGAGCAGGAA-3'; PGRMC2, forward 5'-GGCAATGTTATT TAACAGGTCACCA-3', reverse 5'-TCCACAACCAGTCTTCAGCAA-3'. The primers sequences of rats were as follows: NPRA, forward 5'-TGGAGACACAGTCAA
CACAGCTTC-3', reverse 5'-TCCAGCACAGCCTTGGTCTC-3'; NPRC, forward 5'-ACA CGGCATGACCAGTGGAG-3', reverse 5'-TCAGCAGGGTGACTGTTTGGAG-3'; PG RMC1, forward 5'-CACCTGGTAATTGGCAGTTGGA-3', reverse 5'-ACCACATAA CCATTGCCCTGCTA-3'; PGRMC2, forward 5'-TTTGAACGCAGTGCAGATGG-3', reverse 5'-GGTACGAGTTGCAGTTCTGAAGG-3'.

Western blot. Protein samples were extracted with lysis buffer. $15 \mu \mathrm{g}$ protein samples from each group were loaded onto the SDS polyacrylamide gel for electrophoresis and transferred to NC membranes (Millipore, Billerica, MA, USA). After blocking in $5 \%$ non-fat milk at room temperature for $2 \mathrm{~h}$, primary antibodies: NPRA (1:1000; Santa Cruz Biotechnology), NPRC (1:1000; Santa Cruz Biotechnology), PGRMC1 (1:1000; Cell Signaling), PGRMC2 (1:1000), Bax (1:2000; Proteintech), Bcl-2 (1:2000; Proteintech), Caspase 8 (1:1000; Proteintech), Caspase 9 (1:1000; Proteintech), PCNA (1:2000; Proteintech), EGFR (1:500; Proteintech), p-EGFR (1:500; Cell Signaling), ERK 1/2 (1:500; Beyotime Biotechnology), p-ERK 1/2 (1:500; Beyotime Biotechnology), p-c-Fos (1:500; Cell Signaling), c-Fos (1:500; Cell Signaling), p-c-Jun (1:500; Cell Signaling), c-Jun (1:500; Cell Signaling) and GAPDH (1:2000; Proteintech) were incubated at $4{ }^{\circ} \mathrm{C}$ overnight. Next day, secondary antibodies (1:2000; Cell Signaling) were incubated for $45 \mathrm{~min}$ at room temperature. ECL detection system was used to visualize the bands. All experiments were repeated at least three separate times.

Immunohistochemistry. Paraffin-embedded rat ovary tissues were prepared, followed by deparaffinization and rehydration. After antigen exposed, tissue slides were incubated with $3 \% \mathrm{H}_{2} \mathrm{O}_{2}$ for 10 min and goat serum for 30 min to block non-specific binding. Primary antibodies: ANP (1:100; Abcam, Cambridge, UK), NPRA (1:100; Santa Cruz Biotechnology), NPRC (1:100; Santa Cruz Biotechnology), PGRMC1 (1:50; Cell Signaling), PGRMC2 (1:50; Cell Signaling), PCNA (1:200; Proteintech), p-c-Fos (1:50; Cell Signaling), c-Fos (1:50; Cell Signaling), p-cJun (1:50; Cell Signaling) and c-Jun (1:50; Cell Signaling) were incubated overnight at $4{ }^{\circ} \mathrm{C}$. The second antibody was incubated for $40 \mathrm{~min}$ after washing with PBS. The signals were visualized with $D A B$ wherein yellowish-brown stain indicated as a positive result. The negative control was obtained by replacing primary antibody with PBS. Images were taken under an inverted microscope.

Cell Counting Kit-8 assay. $1 \times 10^{3}$ cells were plated in a 96-well plate and treated with RU486 $\left(10^{-5} \mathrm{M}\right)$, ANP $\left(10^{-7} \mathrm{M}\right)$ or PGRMC1 siRNA $(50 \mathrm{nM})$. Cell Counting Kit-8 (CCK-8, Dojindo Laboratories, Kumamoto, Japan) was added to the cell culture medium. Absorbance at $450 \mathrm{~nm}$ was measured and data were recorded after incubation at $37^{\circ} \mathrm{C}$ for $2 \mathrm{~h}$. All tests were repeated at least three times.

Colony formation assay. Cells were plated in six-well plates containing DMEM/F12 with $10 \%$ FBS after treatment with RU486 $\left(10^{-5} \mathrm{M}\right)$, ANP $\left(10^{-7} \mathrm{M}\right)$ or PGRMC1 siRNA ( $50 \mathrm{nM})$. Colonies were fixed and stained with crystal violet for $20 \mathrm{~min}$ after growing for 7-10 days. Images of surviving colonies were captured and colony numbers were counted.

TUNEL assay. Apoptotic cells analysis was performed using the terminal deoxynucleotidyl transferase-mediated dUTP nick-end labeling (TUNEL) staining kit (Roche, Mannheim, Germany) according to the protocol. Cells grown on glass coverslips were fixed with $4 \%$ paraformaldehyde followed by primary antibody incubation. DAPI was used to counterstain the nuclei. The TUNEL-positive cells had a pyknotic nucleus with dark green fluorescent staining, which was an indicator of apoptosis. Images were taken with an inverted microscope.

Immunoprecipitation. Cells were lysed with RIPA buffer (Beyotime) containing protease and phosphatase inhibitors. Cell lysates were incubated with NPRA $(2 \mu \mathrm{g} / \mathrm{ml}$; Santa Cruz Biotechnology) or PGRMC1 $(2 \mu \mathrm{g} / \mathrm{ml}$; Cell Signaling) antibodies. The IPs were performed overnight, followed with protein A/G sepharose added (Thermo Fisher Scientific, Waltham, MA, USA). The beads were collected by centrifugation and then washed with lysis buffer. Samples were boiled in SDS-PAGE buffer for $5 \mathrm{~min}$ to elute the protein bound to the beads. The final immunoprecipitaions were subjected to western blot analysis.

Fertility assessment. To assess the effects of ANP on fertility, female rats from RU486-induced PCOS rats and ANP treatment group mated with male rats. Successful mating was defined by the discovery of a vaginal plug next day. Female rats were killed to confirm pregnancy at gestational day 10 (GD10). 
Scanning electron microscope. Endometrium tissues collected from PCOS rats and ANP-treated rats at gestational day 4 (GD4) were fixed in $4 \%$ paraformaldehyde and postfixed in $2 \%$ osmium tetroxide. Then dehydrated with a series of ethanol: $95 \%$ ethanol, absolute ethanol and acetone. The surface of the endometrium was scanned with a scanning electron microscope (S-3700N; Hitachi, Tokyo, Japan) after coated with gold.

Statistical analysis. At least three independent experiments were performed for each group. Results were expressed as mean \pm S.E.M. from at least three independent experiments. Differences between groups were analyzed with Student's $t$-test. The significance was defined as $P<0.05$. SPSS 22.0 (IBM, Chicago, IL, USA) was used for the analysis.

\section{Conflict of Interest}

The authors declare no conflict of interest.

Acknowledgements. This study was supported by the National Natural Science Foundation of China (Grant Nos 31670810, 31770857 and 81650011).

\section{Publisher's Note}

Springer Nature remains neutral with regard to jurisdictional claims in published maps and institutional affiliations.

1. De Leo V, Musacchio MC, Cappelli V, Massaro MG, Morgante G, Petraglia F. Genetic, hormonal and metabolic aspects of PCOS: an update. Reprod Biol Endocrinol 2016; 14: 1-17.

2. Weickert MO, Hodges $P$, Tan BK, Randeva HS. Neuroendocrine and endocrine dysfunction in the hyperinsulinemic PCOS patient: the role of metformin. Minerva Endocrinol 2012; 37: 25-40.

3. Rashidi BH, Gorginzadeh M, Aalipour S, Sills ES. Age related endocrine patterns observed in polycystic ovary syndrome patients vs. ovulatory controls: descriptive data from a university based infertility center. Arch Endocrinol Metab 2016; 60: 486-491.

4. Barzilay E, Yung Y, Shapira L, Haas J, Ophir L, Yerushalmi GM et al. Differential expression of poliovirus receptor, regulator of G-protein signaling 11 and erythrocyte protein band 4.1like 3 in human granulosa cells during follicular growth and maturation. Gynecol Endocrinol 2014; 30: 660-663.

5. Carvalho ER, Martins T, Lamb GC, Vasconcelos JL. Ovulation time in suckled beef cows is anticipated by use of low doses of progesterone and temporary calf removal on fixed timed $\mathrm{Al}$ protocol. Theriogenology 2016; 86: 2238-2243.

6. Reynaud K, Saint-Dizier M, Tahir MZ, Havard T, Harichaux G, Labas V et al. Progesterone plays a critical role in canine oocyte maturation and fertilization. Biol Reprod 2015; 93: 1-9.

7. Haouzi D, Bissonnette L, Gala A, Assou S, Entezami F, Perrochia $\mathrm{H}$ et al. Endometrial receptivity profile in patients with premature progesterone elevation on the day of HCG administration. Biomed Res Int 2014; 2014: 1-10.

8. Di Renzo GC, Giardina I, Clerici G, Brillo E, Gerli S. Progesterone in normal and pathological pregnancy. Horm Mol Biol Clin Investig 2016; 27: 35-48.

9. Ebrahimi-Mamaghani M, Saghafi-Asl M, Pirouzpanah S, Aliasgharzadeh A, Aliashrafi S, Rezayi $\mathrm{N}$ et al. Association of insulin resistance with lipid profile, metabolic syndrome, and hormonal aberrations in overweight or obese women with polycystic ovary syndrome. J Health Popul Nutr 2015; 33: 157-167.

10. Huang B, Li Z, Ren X, Ai J, Zhu L, Jin L. Free radical scavenging window of infertile patients with polycystic ovary syndrome: correlation with embryo quality. Front Med 2017; 11: 247-252.

11. Wessel L, Balakrishnan-Renuka A, Henkel C, Meyer HE, Meller K, Brand-Saberi B et al. Long-term incubation with mifepristone (MLTI) increases the spine density in developing Purkinje cells: new insights into progesterone receptor mechanisms. Cell Mol Life Sci 2014; 71: $1723-1740$

12. Weisberg E, Croxatto HB, Findlay JK, Burger HG, Fraser IS. A randomized study of the effect of mifepristone alone or in conjunction with ethinyl estradiol on ovarian function in women using the etonogestrel-releasing subdermal implant, Implanon. Contraception 2011; 84: $600-608$.

13. Brown A, Cheng L, Lin S, Baird DT. Daily low-dose mifepristone has contraceptive potential by suppressing ovulation and menstruation: a double-blind randomized control trial of 2 and 5mg per day for 120 days. J Clin Endocrinol Metab 2002; 87: 63-70.

14. Niinimäki M, Ruokonen A, Tapanainen JS, Järvelä IY. Effect of mifepristone on the corpus luteum in early pregnancy. Ultrasound Obstet Gynecol 2009; 34: 448-453.

15. Cuevas CA, Tapia-Pizarro A, Salvatierra AM, Munroe DJ, Velasquez L, Croxatto HB. Effect of single post-ovulatory administration of mifepristone (RU486) on transcript profile during the receptive period in human endometrium. Reproduction 2016; 151: 331-349.

16. Peluso JJ, Griffin D, Liu X, Horne M. Progesterone receptor membrane component-1 (PGRMC1) and PGRMC-2 interact to suppress entry into the cell cycle in spontaneously immortalized rat granulosa cells. Biol Reprod 2014; 91: 1-12.
17. Sueldo C, Liu X, Peluso JJ. Progestin and AdipoQ Receptor 7, Progesterone Membrane Receptor Component 1 (PGRMC1), and PGRMC2 and their role in regulating progesterone's ability to suppress human granulosa/luteal cells from entering into the cell cycle. Biol Reprod 2015; 93: 1-11.

18. Saint-Dizier M, Sandra O, Ployart S, Chebrout M, Constant F. Expression of nuclear progesterone receptor and progesterone receptor membrane components 1 and 2 in the oviduct of cyclic and pregnant cows during the post-ovulation period. Reprod Biol Endocrinol 2012; 10: 1-12.

19. Bunch K, Tinnemore D, Huff S, Hoffer ZS, Burney RO, Stallings JD. Expression patterns of progesterone receptor membrane components 1 and 2 in endometria from women with and without endometriosis. Reprod Sci 2014; 21: 190-197.

20. Zhang L, Kanda Y, Roberts DJ, Ecker JL, Losel R, Wehling $M$ et al. Expression of progesterone receptor membrane component 1 and its partner serpine 1 mRNA binding protein in uterine and placental tissues of the mouse and human. Mol Cell Endocrinol 2008; 287: 81-89.

21. Peluso JJ. Progesterone receptor membrane component 1 and its role in ovarian follicle growth. Front Neurosci 2013; 7: 1-7.

22. Peluso JJ, Yuan A, Liu X, Lodde V. Plasminogen activator inhibitor 1 RNA-binding protein interacts with progesterone receptor membrane component 1 to regulate progesterone's ability to maintain the viability of spontaneously immortalized granulosa cells and rat granulosa cells. Biol Reprod 2013; 88: 1-10

23. Cahill MA, Jazayeri JA, Catalano SM, Toyokuni S, Kovacevic Z, Richardson DR. The emerging role of progesterone receptor membrane component 1 (PGRMC1) in cancer biology. Biochim Biophys Acta 2016; 1866: 339-349.

24. Elassar A, Liu X, Scranton V, Wu CA, Peluso JJ. The relationship between follicle development and progesterone receptor membrane component-1 expression in women undergoing in vitro fertilization. Fertil Steril 2012; 97: 572-578.

25. Schuster J, Karlsson T, Karlström PO, Poromaa IS, Dahl N. Down-regulation of progesterone receptor membrane component 1 (PGRMC1) in peripheral nucleated blood cells associated with premature ovarian failure (POF) and polycystic ovary syndrome (PCOS). Reprod Biol Endocrinol 2010; 8: 1-6.

26. Song $W$, Wang $H$, Wu $Q$. Atrial natriuretic peptide in cardiovascular biology and disease (NPPA). Gene 2015; 569: 1-6.

27. Zhang M, Tao Y, Zhou B, Xie H, Wang F, Lei $L$ et al. Atrial natriuretic peptide inhibits the actions of FSH and forskolin in meiotic maturation of pig oocytesvia different signalling pathways. J Mol Endocrinol 2005; 34: 459-472.

28. Dineva J, Vangelov I, Nikolov G, Gulenova D, Ivanova M. Atrial natriuretic peptide is an antiapoptotic factor for human granulosa luteinized cells with impact on the results of $\mathrm{COH} /$ IVF in women undergoing IVF program. J Obstet Gynaecol Res 2011; 37: 511-519.

29. Vollmar AM, Mytzka C, Arendt RM, Schulz R. Atrial natriuretic peptide in bovine corpus luteum. Endocrinology 1988; 123: 762-767.

30. Gutkowska J, Jankowski M, Sairam MR, Fujio N, Reis AM, Mukaddam-Daher S et al. Hormonal regulation of natriuretic peptide system during induced ovarian follicular development in the rat. Biol Reprod 1999; 61: 162-170.

31. Lauria PB, Del Puerto HL, Reis AM, Candido AL, Reis FM. Low plasma atrial natriuretic peptide: a new piece in the puzzle of polycystic ovary syndrome. J Clin Endocrinol Metab 2013: 98: 4882-4889.

32. Noubani A, Farookhi R, Gutkowska J. B-type natriuretic peptide receptor expression and activity are hormonally regulated in rat ovarian cells. Endocrinology 2000; 141: 551-559.

33. Kobayashi S, Acosta TJ, Ozawa T, Hayashi K, Berisha B, Ohtani M et al. Intraluteal release of angiotensin II and progesterone in vivo during corpora lutea development in the cow: effect of vasoactive peptides. Biol Reprod 2002; 66: 174-179.

34. Misono KS, Philo JS, Arakawa T, Ogata CM, Qiu Y, Ogawa H et al. Structure, signaling mechanism and regulation of the natriuretic peptide receptor guanylate cyclase. FEBS $J$ 2011: 278: 1818-1829.

35. Hotchkiss A, Feridooni T, Baguma-Nibasheka M, McNeil K, Chinni S, Pasumarthi KB. Atrial natriuretic peptide inhibits cell cycle activity of embryonic cardiac progenitor cells via its NPRA receptor signaling axis. Am J Physiol Cell Physiol 2015; 308: C557-C569.

36. Zhang M, Tang H, Shen G, Zhou B, Wu Z, Peng Z et al. Atrial natriuretic peptide induces an acrosome reaction in giant panda spermatozoa and enhances their penetration of salt-stored porcine oocytes. Theriogenology 2005; 64: 1297-1308.

37. Setji TL, Brown AJ. Polycystic ovary syndrome: update on diagnosis and treatment. Am J Med 2014; 127: 912-919.

38. Kar S. Clomiphene citrate or Letrozole as first-line ovulation induction drug in infertile PCOS women: a prospective randomized trial. J Hum Reprod Sci 2012; 5: 262-265.

39. Baruah J, Roy KK, Rahman SM, Kumar S, Sharma JB, Karmakar D. Endometrial effects of letrozole and clomiphene citrate in women with polycystic ovary syndrome using spiral artery Doppler. Arch Gynecol Obstet 2009; 279: 311-314.

40. Seyedoshohadaei F, Tangestani L, Zandvakili F, Rashadmanesh N. Comparison of the effect of clomiphene-estradiol valerate vs letrozole on endometrial thickness, abortion and pregnancy rate in infertile women with polycystic ovarian syndrome. J Clin Diagn Res 2016; 10: QC10-QC13

41. Moriyama T, Hagihara S, Shiramomo T, Nagaoka M, Iwakawa S, Kanmura Y. The protective effect of human atrial natriuretic peptide on renal damage during cardiac surgery. $J$ Anesth 2017; 31: 163-169.

42. Nojiri $T$, Yamamoto $H$, Hamasaki $T$, Onda $K$, Ohshima $K$, Shintani $Y$ et al. A multicenter randomized controlled trial of surgery alone or surgery with atrial natriuretic peptide in lung cancer surgery: study protocol for a randomized controlled trial. Trials 2017; 18: 183. 
43. Croxatto HB, Kovács L, Massai R, Resch BA, Fuentealba B, Salvatierra AM et al. Effects of long-term low-dose mifepristone on reproductive function in women. Hum Reprod 1998; 13: 793-798.

44. Danielsson KG, Marions L, Bygdeman M. Effects of mifepristone on endometrial receptivity. Steroids 2003; 68: 1069-1075.

45. Marions L, Cekan SZ, Bygdeman M, Gemzell-Danielsson K. Effect of emergency contraception with levonorgestrel or mifepristone on ovarian function. Contraception 2004; 69: 373-377.

46. Cameron ST, Critchley HO, Thong KJ, Buckley CH, Williams AR, Baird DT. Effects of daily low dose mifepristone on endometrial maturation and proliferation. Hum Reprod 1996; 11: 2518-2526.

47. Gemzell-Danielsson K, Svalander P, Swahn ML, Johannisson E, Bygdeman M. Effects of a single post-ovulatory dose of RU486 on endometrial maturation in the implantation phase. Hum Reprod 1994; 9: 2398-2404.

48. Singh KB. Persistent estrus rat models of polycystic ovary disease: an update. Fertil Steril 2005; 84: 1228-1234

49. Lakhani K, Yang W, Dooley A, El-Mahdi E, Sundaresan M, McLellan S et al. Aortic function is compromised in a rat model of polycystic ovary syndrome. Hum Reprod 2006; 21: 651-656.

50. Chatelain D, Lesage J, Montel V, Chatelain A, Deloof S. Effect of natriuretic peptides on in vitro stimulated adrenocorticotropic hormone release and pro-opiomelanocortin mRNA expression by the fetal rat pituitary gland in late gestation. Horm Res 2003; 59: 142-148.
51. Large MJ, Wetendorf M, Lanz RB, Hartig SM, Creighton CJ, Mancini MA et al. The epidermal growth factor receptor critically regulates endometrial function during early pregnancy. PLOS Genet 2014; 10: 1-18.

52. Ahmed IS, Rohe HJ, Twist KE, Craven RJ. Pgrmc1 (progesterone receptor membrane component 1) associates with epidermal growth factor receptor and regulates erlotinib sensitivity. J Biol Chem 2010; 285: 24775-24782.

cc (i) Cell Death and Disease is an open-access journal published by Nature Publishing Group. This work is

licensed under a Creative Commons Attribution 4.0 International License. The images or other third party material in this article are included in the article's Creative Commons license, unless indicated otherwise in the credit line; if the material is not included under the Creative Commons license, users will need to obtain permission from the license holder to reproduce the material. To view a copy of this license, visit http://creativecommons.org/licenses/by/4.0/

(C) The Author(s) 2017 